\title{
EDUCATING ENGINEERS FOR A GLOBAL WORLD
}

\author{
James L. Melsa \\ President, American Society for Engineering Education, Washington, DC, USA, and Dean Emeritus, College \\ of Engineering, Iowa State University, Ames Iowa, USA, melsa@iastate.edu
}

\begin{abstract}
For many years, the American Society for Engineering Education (ASEE) and others have been studying the role of the engineer and engineering education in the $21^{\text {st }}$ century. More specifically, the organization has looked at changes needed to effectively address these evolving roles; their recommendations are included in a definitive report titled Transforming Engineering through Educational Scholarship. As the practice of engineering becomes increasingly global, ASEE is strengthening its connections to the worldwide engineering education community. Of particular note is ASEE's leadership in the development of the International Federation of Engineering Education Societies (IFEES). ASEE has also been working with other engineering education societies to sponsor a series of global colloquia on engineering education in a variety of countries. The engineering profession is critical to economic development, quality of life, and security of all countries. The ASEE must work with other engineering organizations to advance the image of engineering and to draw more people into the profession.
\end{abstract}

Keywords: globalization, transformation, image, engineering education

\section{Background}

Founded in 1893, the American Society for Engineering Education (www.asee.org) is a nonprofit organization of individuals and institutions committed to furthering education in engineering and engineering technology. It accomplishes this mission by promoting excellence in instruction, research, public service, and practice; exercising worldwide leadership; fostering the technological education of society; and providing quality products and services to members.

In its pursuit of academic excellence, ASEE develops policies and programs that enhance professional opportunities for engineering faculty members, and promotes activities that support increased student enrollments in engineering and engineering technology programs in colleges and universities. Strong communication and collaboration with national and international organizations further advances ASEE's mission.

ASEE also fulfills its mission by providing a valuable communication link among corporations, government agencies, and educational institutions. The organization has more than 13,000 members, including deans, department heads, faculty members, students, and government and industry representatives who represent all disciplines of engineering and engineering technology. ASEE's organizational membership is composed of 400 engineering and engineering technology colleges and affiliates, more than 50 corporations, and numerous government agencies and professional associations. Many of its efforts are directed at facilitating open and ongoing dialogues among these groups.

This paper reviews ASEE's current activities in three critical areas: 1) transforming engineering education; 2) the globalization of engineering education; and 3) enhancing the reputation of engineering in the United States.

\section{Transforming Engineering Education}

Changes in the practice of engineering have created the need to modify the content of engineering programs - in other words, changing what students need to learn. Much of the structure of the educational system was set in the 1950s when the practice was very different. It is obvious that engineering is now conducted on a global scale. In a recent informal survey, U.S. engineering deans unanimously indicated a belief that engineering education programs must contain an international experience. Many institutions do not offer such programs and even where they're offered, few students take advantage of them. The engineering workplace is heavily teamwork-oriented; at the same time, many engineering professors discourage cooperative work by labeling it "cheating." The engineer of the $21^{\text {st }}$ century will need to be much more socially and environmentally conscious. It is clear that biotechnology, information systems, and nanotechnology will play increasingly important roles in engineering practice in the future. Yet very few engineering programs require any type of life-science experience for their students. The rapid expansion of technical knowledge has caused some people to suggest that engineering should be a five-year course of study. By some estimates, however, the amount of technical information is doubling every two years and therefore, half of what a student learns in his or her first year of study will be outdated by year three. We are currently preparing students for jobs that don't yet exist using technologies that haven't yet been invented in order to solve problems we don't even know are problems.

In 2004, the National Academy of Engineering of the United States released a report entitled The Engineer of

平成 19 年 8 月 4 日講演

†第55回年次大会国際セッションプロシーディングスより 著者の了解を得て転載しました。 
2020: Visions of Engineering in the New Century [1], which concludes with the fact that an engineer in 2020 must be flexible and capable of operating in a world where "social, cultural, political, and economic forces will continue to shape and affect the success of technological innovation." The report goes on to state,

"Given the uncertain and changing character of the world in which 2020 engineers will work, engineers will need something that cannot be described in a single word. It involves dynamism, agility, resilience, and flexibility. Not only will technology change quickly, the social-political-economic world in which engineers work will change continuously. In this context it will not be this or that particular knowledge that engineers will need but rather the ability to learn new things quickly and the ability to apply knowledge to new problems and new contexts."

Change is never easy. As John Kenneth Galbraith noted, "Faced with the choice between changing one's mind and proving that there is no need to do so, almost everybody gets busy on the proof." Engineering faculty members are good with proofs, and it will be easy for them to find reasons why fundamental changes in engineering education cannot happen. The reality is that all organizations, including universities, must become learning organizations [2] that are skilled at creating, acquiring, and transferring knowledge, and at modifying their behavior to reflect their new knowledge and insights. We must take action on what we know about improving engineering education.

Recent scholarly research has identified many ways to strengthen the pedagogy and learning environments for engineering students. How effectively we teach is as important as what we teach, and student learning needs to be our focus. To quote John Dewey [3], "Teaching and learning are correlative or corresponding processes, as much so as selling and buying. One might as well say he has sold when no one has bought, as to say that he has taught when no one has learned." Learning is a process that can be measured and improved. It is clear that we must make a shift from a teaching-based mind set to a learning-based one. Throughout the ages, most schools have spent endless hours trying to teach material that may be better learned [4]. The shift from a teaching-oriented paradigm to a learning-based paradigm is much more than a simple semantic change.

As the administrative hierarchy of education developed, it followed the model of the industrial bureaucracy. This model, with its functional, hierarchical style, was based on the military organization of the 1800s, which was designed to fight trench warfare. The organization of knowledge into permanent disciplines was grounded in old industrial assumptions. Departments were established to serve professors, not students. Rosenzweig's rubric defines the situation that exists throughout academia: "On most major campuses the academic department emerged as the spokesman for and protector of its members. It also became, not by coincidence, the entity of the campus most capable of producing change, and simultaneously, the one least motivated to do so."

While there is ample evidence that U.S. engineering schools provide a technically sound education, there are also many reports from employers that engineering graduates are often too narrowly trained without the inclinations and skills required to contribute their expertise in the complex contexts of today's increasingly global environment. There is also clear evidence that engineering programs are falling short in attracting and retaining those who should form the vanguard of the next generation of engineers. This evidence includes declining interest in engineering education from U.S.-born students and a perception by many women and underrepresented minorities that the climate does not welcome them. Data suggest that bright, capable students are pursuing careers in fields other than engineering because they do not perceive engineering education as a path to a stimulating, fulfilling career; they see, instead, a difficult, dry, and dull curriculum based on a model conceived several decades before they were born. Engineering education has traditionally responded to such concerns with episodic calls for reform with little or no basis in educational scholarship. These efforts have not resulted in the kind of transformational change now needed to attract and retain intellect and talent to engineering.

We know a great deal about how to improve engineering education. Scholarly research has identified areas for improvement, both in the content of engineering programs and in the pedagogy and learning environments for engineering students. ASEE must lead an endeavor to enhance the scholarship of engineering education and to share and disseminate best practices. Using successful, documented approaches, we must improve engineering education to the benefit of the future engineering workforce and the societies it will serve.

There is some evidence that transformational changes are occurring. The National Science Foundation is investing heavily in programs in the United States to improve K-12 curricula in mathematics and science as well as engineering education. Several top-tier engineering programs have recently created departments focused on engineering education. In the last few years, ASEE has changed the mission of its Journal of Engineering Education to focus on research in engineering education. The National Academy of Engineering has undertaken several efforts including the creation of the Center for the Advancement of Scholarship on Engineering Education as well as the report noted above.

During this academic year, ASEE has been engaged in a Year of Dialogue. Initiated at the 2006 ASEE Annual Conference with a panel session featuring a number of leading experts in engineering education, the goal of this ongoing effort is to engage the ASEE membership in the task of defining "what and how should we teach to produce engineers who will be leaders in the global community." A special emphasis of the discussions was the role of the "scholarship of teaching and learning in engineering education" to help to define the best methods and practices for enhancing student learning. This dialog will be documented and transformed into meaningful action plans with a 
challenge to fundamentally improve engineering education. This challenge will be delivered initially in a report entitled Transforming Engineering Education through Educational Scholarship that speaks to the goals of the engineering community (e.g., more globally competitive engineers, improved student learning, enhanced retention, greater diversity, etc.). The focus of this report will be on scholarship in engineering education including a definition of what it is, benefits derived from it, and how best to foster it. Specifically this report seeks to advance the following outcomes:

1. Improve engineering education to better prepare graduates to compete and contribute in the global marketplace.

2. Promote and support foundational engineering education scholarship that will result in a new body of knowledge that will drive and guide new program developments and innovations in engineering education.

3. Continue research and collaboration on innovations in engineering education and application of that research to improve our programs.

4. Develop an active community for sharing best practices confirmed by scholarship, possibly in the form of a national database.

5. Provide regular, practice-proven or research-based faculty development and training in engineering education.

6. Increase rewards and incentives for faculty to pursue excellence in the scholarship of discovery, integration, application, and teaching related to engineering education.

7. Welcome active participation and voice for industry in the education of engineers. A greater premium needs to be placed on industry experience in the recruitment and retention of faculty. We need to strengthen exchanges between industry and academe - having practitioners teach and teachers practice.

8. Establish a downstream mechanism for assessing the impact of this report and keeping it current.

Using this report as a roadmap, ASEE will urge U.S. engineering educators to put these results into practice, including sharing of findings and implementations of best practices.

\section{Globalization}

The value of an international experience, in the context of engineering education, has been the subject of much activity and research. A recent study, In Search of Global Engineering Excellence [5], summarizes the majority of these findings: "The ability to live and work in a global community is -- today -- an important requirement for engineering graduates. They need to have broad engineering skills and know-how, and to be flexible and mobile, and able to work internationally. Regrettably, the fulfillment of this international cognizance within the United States has gone largely unmet. Study and work abroad programs are driven by the priorities and plans of an educational institution, and when there is cooperation among universities, it is usually only ad hoc at best."

The need for a global perspective in engineering education is, perhaps, best understood from a quote by Peter Drucker [6], "In the new mental geography created by the railroad, humanity mastered distance. In the mental geography of e-commerce, distance has been eliminated. There is only one economy and only one market." As Friedman [7] notes, the world is becoming flat-economic competition between industrial countries and emerging market countries can no longer be separated. As an example, India and China are rapidly entering the complex global supply chains, primarily due to the Internet. A flat world requires U.S. engineers to be capable of working in a global context, whether they're employed within the United States or internationally. This fact is becoming apparent throughout U.S. organizations, with national engineering groups emphasizing the importance of learning outcomes and related skills development for engineering students.

The accrediting criteria in the United States (ABET's Engineering Criteria 2000 [8] (EC 2000)) are also helping to raise the national awareness of the growing globalization of engineering practice. Although EC 2000 does not specifically require an international experience for a program to be accredited, there is little question that international experiences enhance a number of elements of the criteria including:

- Criterion 3.c, which specifies that engineering programs must demonstrate that their students attain "an ability to design a system, component, or process to meet desired needs within realistic constraints such as economic, environmental, social, political..."

- Criterion 3.h, which requires "the broad education necessary to understand the impact of engineering solutions in a global, economic, environmental, and societal context."

- Criterion 3.j, which calls for knowledge of contemporary issues."

An engineering program demonstrates that it meets these outcomes through various learning experiences within and complementary to the curriculum. International experiences typically encompass aspects of these outcomes.

The Engineer of 2020 Report [1] makes a number of important conclusions relative to the importance of global awareness. Paralleling The World is Flat, the report states, 
"Advances in communications, travel, and economics have created a world where no country is untouched by any other. In the United States the oceans that bound our coasts no longer insulate us from other nations. In this dynamic global economy and political environment, engineering must adjust to a new world view."

"We aspire to a future where engineers are prepared to adapt to changes in global forces and trends and to ethically assist the world in creating a balance in the standard of living for developing and developed countries alike."

A recent non-scientific survey [9] of U.S. engineering deans reveals some interesting, although not surprising results regarding the nature of international activities in engineering programs. When asked, "Does your college believe that an international experience for undergraduate students is important? If so, why?" all responded affirmatively. Despite this strong showing, a few schools indicated that a lack of faculty support and/or financial conditions make it difficult or impossible to have a meaningful international program. This finding is worrisome: The initiative for international experiences often begins with the administration. Successful programs require full support that that level.

When engineering deans were asked if their colleges had one or more programs for undergraduate students to increase their international knowledge/experience, about 15\% said they rely on their university-wide study abroad offices for this effort. Others reported having their own engineering-specific study abroad programs; many of these were new and/or rapidly expanding. A small number of respondents said that difficulty in attracting students to international programs and other factors precluded the existence of any sort of offering. It is important to realize that although it may be difficult to encourage study abroad programs, especially in these early stages of raising national awareness, the opportunity for a student to gain an international experience must at least exist.

Colleges indicated that they have created international programs for a number of reasons ranging from the need for engineers to be internationally cognizant to the chance for students to partake in an educational experience that cannot be replicated in any other way. Survey results also showed that only a few colleges have any formal approach to evaluating the effectiveness of their programs, although almost all reported strong anecdotal feedback from students who had had an international experience. This result is not surprising since so many of the international programs are recently developed.

Finally, the survey indicated that less than $14 \%$ of United States engineering undergraduate students have had an international experience by the time they graduate. Since many engineering international programs are new and/or expanding rapidly, this percentage is expected to increase. As an example of the growth of interest in international activities, the Proceedings of the 2005 ASEE Annual Conference and Exposition listed approximately 25 papers addressing international activities, while the Proceedings of the 2006 ASEE Annual Conference and Exposition listed 50 papers of a similar nature.

In the past five years, the ASEE has undertaken two major activities to enhance its global presence and expand opportunities for U.S. engineering faculty members to have meaningful international experiences that will translate to possible experiences for their students. Several key events contributed to ASEE's increasing visibility in the international arena:

Since 2002, ASEE has sponsored an annual global colloquium for engineering education. The inaugural event was held in Berlin, Germany. The goal of these colloquia is to bring together engineering educators from across the world to discuss common issues and innovative approaches to address them. Subsequent colloquia have been held in Nashville, TN, USA; Beijing, China; and Sydney, Australia. The $5^{\text {th }}$ Global Colloquium in Brazil far exceeded expectations - over 450 representatives from 34 countries participated, building a network of collaboration and partnership among Brazilian, U.S. and Latin American universities and institutions such as the Organization of American States, the World Bank, and corporate representatives. At this colloquium, a newly created ASEE Student Forum convened with over 50 students from many countries participating; financial support from several corporate sponsors aided the students in being able to attend. The next colloquium will be held in Istanbul, Turkey, hosted by Bosporus University. Future sites are Cape Town, South Africa, 2008; Hungry, 2009; and Singapore, $2010 . \quad$ ASEE currently has more than 700 global online members who receive the monthly ASEE Action International e-newsletter and have access to ASEE's electronic publications.

The global colloquium in Brazil served as the platform for the inaugural meeting of the International Federation for Engineering Education Societies (IFEES). The goal of the member societies of IFEES (see website www.ifees.net for a current list of members) is to work collaboratively to establish and strengthen effective, quality worldwide engineering education processes to assure a global supply of well-prepared engineering graduates. IFEES will attract corporate participation, helping to connect engineering graduates with international corporations that have a pressing need for well-trained engineers who can work in a global environment. The group will also enhance the ability of engineering faculty, students, and practitioners to understand the varied cultures of the world and work effectively in them. At this first meeting, the president, four vice presidents and an executive committee representing all regions of the world were elected by the 31 founding member institutions represented by an impressive aggregation of engineering and corporate leaders. The discussion focused on future IFEES activities; the next meeting of IFEES will be held at the global colloquium in Turkey. 


\section{Enhancing the Image}

By some estimates, 25 percent of the current U.S. engineering workforce, most of which were educated right after the Sputnik era of the late 1950s, will be eligible for retirement in the next five years. There is also clear evidence that U.S. engineering education programs often fall short in attracting and retaining those who should form the vanguard of the next generation of engineers. This evidence includes declining interest in engineering education from U.S.-born students and a perception by many women and underrepresented minorities that the climate does not welcome them. Though the enrollment of women at most universities is now approaching $60 \%$, the enrollment of women in engineering programs is only about $20 \%$. This compares to other professional fields like law and medicine, where females comprise more than half of the student enrollment. The problem is exacerbated by the fact that more engineering graduates are going into non-engineering fields such as finance, medicine, and law.

ASEE is deeply concerned about these trends and has recently undertaken several activities to address them. One of the targeted activities deals with pre-college (K-12) preparation. The ASEE K-12 \& Pre-College Engineering division provides a focus for development of innovative K-12 engineering education curricula and delivery approaches and a forum for the following activities: presenting and sharing K-12 engineering educational initiatives and methods; creating a vital community engaged in K-12 engineering initiatives; encouraging the professional development of teachers in K-12 engineering education methodologies; increasing awareness and participation of university faculty and industrial educators/partners in K-12 engineering initiatives; promoting engineering as the context to integrate science and mathematics with all subjects in the K-12 setting; encouraging the participation of K-12 educators in the creation and delivery of K-12 engineering content; and synthesizing and broadly disseminating lessons learned.

ASEE's national leadership profile in K-12 engineering activities continues to expand. The very popular magazine; Engineering, Go For It! serves as a flagship product for spreading the word about the rewards of study and work in engineering. With the publication this year of its third edition, ASEE hopes to exceed 1million copies in circulation of all editions.

The third annual ASEE Workshop on K-12 Engineering Education in Chicago attracted 175 attendees, about half coming from K-12 communities and half from higher education, non-profit, and industry groups. The event featured 23 technical sessions and plenary speeches from national and Chicago-area leaders in K-12 STEM education. A diverse group of sponsors supported the event; proceedings are available on our K-12 website, along with many other K-12 engineering resources developed by ASEE. The fourth workshop is being planned in conjunction with the 2007 ASEE Annual Conference in Honolulu

ASEE also played leadership roles this year in a variety of other K-12 education activities. We worked on the Deans of Engineering and Deans of Education project to promote campus-based collaborations between faculties in these areas; provided the keynote speaker at the 2006 Wisconsin Technology Education Association meeting; and placed a representative on the advisory boards of three different K-12 projects, one run by a local school district, one by a major research university, and one by a non-profit education organization.

The ASEE Women in Engineering Division is concerned with all matters affecting the recruitment and retention of women students in engineering and the re-entry of women into the profession. It is active in the sponsorship of workshops, has published a series of pamphlets on the re-entry issue, and maintains an active schedule of papers and workshops at the ASEE Annual Conference.

The ASEE Minorities in Engineering Division works to increase the participation of Black/African, Hispanic/Latino, and Native/Pacific Islander Americans at all levels of engineering education and the profession. The division is concerned with programs to improve preparation, recruitment and retention of students at pre-college, undergraduate and graduate levels in the science, mathematics, and engineering fields, and with the need to increase the number of minority SME faculty. The division sponsors sessions at the ASEE Annual Conference and administers the Vincent Bendix Minorities in Engineering Award.

\section{Conclusion}

Since its founding more than 100 years ago, ASEE has been concerned with enhancing all phases of engineering education in the United States. Never before has its mission been more critical and more challenging. Faced with the rapidly changing environment of engineering practice, it clear than the education of engineers must change in response. This paper has shown how the society is addressing important issues regarding the transformation of engineering education, globalization, and the need to enhance the image of engineering.

\section{References}

1 National Academy of Engineering, The Engineer of 2020: Visions of Engineering in the New Century, Washington, DC, 2004.

2 David Garvin, Building a Learning Organization, Harvard Business Review, July-Aug 1993

3 John Dewey, How We Think, pp 29, D. C. Heath \& Co., New York, 1910

4 C. R. Christensen, et. al., Education for Judgment, Harvard Business School Press, 1991

5 Tricia Grindel, (editor), In Search of Global Engineering Excellence, Continental AG, Hanover, Germany, 2006.

6 Peter Drucker. Managing in the Next Society, St. Martin's Press. New York, 2002. 
Thomas L Friedman, The World is Flat: A Brief History of the Twenty-first Century, Farrar, Straus, and Giroux, 2005.

8 Engineering Accreditation Commission, Criteria for Accrediting Engineering Programs, ABET, Inc., Baltimore, MD, 2006.

9 Andrew Riha, et. al., Growing Globalization of Engineering Practice: Raising National Awareness, Proceeding of the 2007 ASEE Annual Conference

\section{Biography}

Dr. Melsa is the Dean Emeritus of the College of Engineering at Iowa State University; he served as dean from 1995 to 2004. Previously, he spent 11 years at Tellabs Inc., Lisle, Ill, a telecommunications equipment manufacturer, including several vice-presidential appointments. Melsa also was a department chair at the University of Notre Dame for 11 years and he was as a faculty member at Southern Methodist University, Dallas, and the University of Arizona, Tucson. He was named a fellow of the Institute of Electrical and Electronic Engineers in 1978 and of the American Society for Engineering Education in 2006. He has an extensive record of service to national and international groups, including the Malcolm Baldrige National Quality Award. Melsa received his B.S. degree in electrical engineering from Iowa State (1960) and his M.S. (1962), and Ph.D. (1965) degrees from the University of Arizona. 